\title{
The Research for Class Application of EPUB Electronic Teaching Materials
}

\author{
Liu Wenlong ${ }^{1 *}$, Yuan Hua ${ }^{1}$,Wang Tianqi ${ }^{1}$, Wang Xiaochun ${ }^{1}$ \\ ${ }^{1}$ Department of Educational Technology, Capital Normal University, Beijing \\ *liuwenlong0110@163.com
}

Keywords: Mobile Devices, EPUB, Electronic Teaching Material, Class Application

\begin{abstract}
This article puts forward that the electronic materials can accomplish the integration of various instructional content as well as theoretical and practical significance of discussing design and application of electronic materials. For the aspect of the application of electronic teaching materials, this paper reputes that we should consider three problems: the Resources construction; Function construction; Mode creation. The class application of electronic materials still needs multi-joint in order to achieve a wide range of application and development.
\end{abstract}

\section{Introduction}

Compared with the traditional teaching materials, electronic materials have the advantage of breaking the limit of time, place, and making the teaching contents more rich. For electronic teaching materials based on the mobile device move into the classroom, which make the class more vivid, the teaching quality will naturally improve. And EPUB electronic materials depend on its various advantages and multi-platform support so that it can be better used in classroom teaching. We discuss from the design process of electronic teaching materials and new teaching model, striving to explore new methods and mode for teachers to raise their teaching quality and students' learning efficiency under the information technology condition.

\section{The application characteristics of the EPUB electronic teaching materials}

The electronic materials are well accepted and the school records are improved after students using electronic teaching materials from the current researches. Electronic teaching materials in EPUB format have good user interface so that students do not feel strange. In addition, teaching material also provides audio, video, and text related multimedia information. Students won't be bored as in the traditional teaching.

The influence on the classroom teaching from electronic materials mainly comes from the change of the classroom teaching mode and elements in classroom teaching. Many researches show that compared classroom using electronic teaching materials with the traditional classroom, there are many differences in many respects, like textbook content, teaching method, learning styles and means of communications. Classroom using electronic teaching materials has advantages in the teaching way and student's study way over many traditional classrooms. As important class activities Teacher-student communication and student-student communication can also easily achieve using electronic teaching material. So using fully functional electronic teaching materials has tremendous significance in classroom teaching.

\section{The application mode of EPUB electronic materials in classroom teaching}

For the influence of device support and resources development and corresponding learning model of EPUB electronic teaching materials, the application of EPUB electronic teaching materials in the school is a gradual process. In order to apply EPUB electronic teaching materials in the teaching application better, there need to be three aspects to explore: (1)resources building, mainly completing the text teaching material's secondary development and collection, arrangement of multimedia information in electronic textbook (2)function building, mainly realizing teaching and reader function of electronic materials; (3)key problems, mainly considering the formation of learning evaluation in the process of using electronic teaching materials. 


\subsection{Design and development of resources}

In the design and development of teaching resources, it is the secondary development of the original text materials, rather than simple electronic of text materials. When opening up the electronic materials, the developers should consider the feelings of learners constantly. So we should design electronic suitable teaching materials for students from the view of the learners, such as friendly interface, students' interest and the students' thinking habits, etc.

There are three procedures to develop electronic teaching material resources as following: the user puts forward the demand; the researchers design; Enterprises develop in batch. The specific process design and development is shown in figure 1.

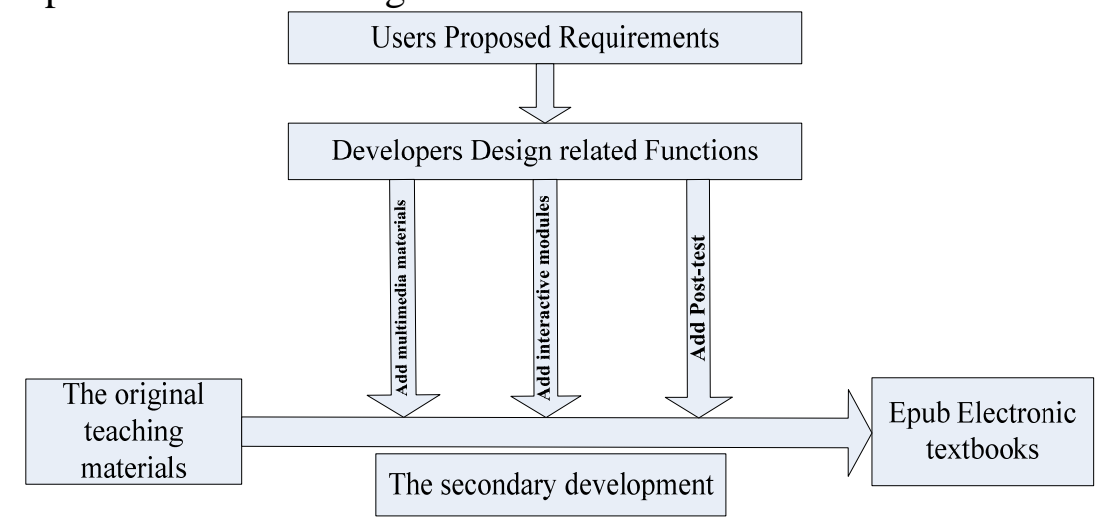

Figure 1 The specific process design and development of electronic material

(1) The user puts forward the demand

The designers communicate with experienced teachers to understand learning activities involved in the language classroom, and record the teacher-student interaction behavior in class. Designers also survey the students, to understand the learners' attitude and recognition to the electronic materials and clarify learners' expected function and requirement, ensuring the friendly function and interface.

(2) Designers design related function according to the demand

This is the secondary development of the original materials. In the whole process, we add multimedia elements teacher-student interaction module and the test module into the original materials, in order to apply electronic teaching materials for teaching activities greater.

(3) Enterprises develop in batch

Developing the original materials is only a research and test. To make the electronic materials EPUB more widely used in classroom teaching, it also needs to rely on enterprises, making the secondary development of teaching material in batch. Only on the premise of abundant resource can the electronic teaching materials be promoted.

\subsection{Function building}

We focus on the development of the electronic materials the development of electronic materials reader. Based on the original materials, we add multimedia elements, interaction and test feedback into electronic teaching materials.

(1) Function building of electronic teaching materials

In the electronic materials' design and production process, we join the rich multimedia elements, in order to adjust learners' burnout thinking in the classroom; On the other hand we also join the real-time test feedback function in text in order to prevent the simple text teaching from bringing about the bored psychology.

In the specific function design, the author thinks it should include the following content: directory function, the text read information, video information, add notes function at any time, bookmark function, teacher-student communication, student-student communication module, the test module after class, evaluation and feedback module. 
Table 1 Specified functionality of electronic teaching materials

\begin{tabular}{|c|c|c|}
\hline \multirow{4}{*}{ body part } & $\begin{array}{l}\text { directory } \\
\text { functionality }\end{array}$ & $\begin{array}{l}\text { provide the complete list materials of; students can link to text } \\
\text { through the directory }\end{array}$ \\
\hline & read functionality & $\begin{array}{l}\text { read the whole text reading and each section; can provide } \\
\text { pronunciation of new words after-school }\end{array}$ \\
\hline & add notes function & $\begin{array}{l}\text { when reading e-books, learners add his own book reports, and } \\
\text { this module can be easily hung up and open }\end{array}$ \\
\hline & bookmark function & record learners' reading progress \\
\hline \multirow[t]{3}{*}{$\begin{array}{l}\text { after-class } \\
\text { part }\end{array}$} & $\begin{array}{l}\text { teacher-students } \\
\text { communication }\end{array}$ & $\begin{array}{l}\text { students can put forward problems and experience, teachers can } \\
\text { give the answer and feedback in the reader. }\end{array}$ \\
\hline & $\begin{array}{l}\text { student-student } \\
\text { communication }\end{array}$ & learners discuss with each other through the modules \\
\hline & the test after class & provide the related test and measure learning effect \\
\hline \multirow[t]{2}{*}{$\begin{array}{l}\text { 'extending' } \\
\text { part }\end{array}$} & video information & $\begin{array}{l}\text { provides the extracurricular material related to the text, broaden } \\
\text { learners' knowledge, and arouse the students' learning interest. }\end{array}$ \\
\hline & $\begin{array}{l}\text { evaluation } \\
\text { feedback }\end{array}$ & $\begin{array}{l}\text { teacher evaluates learners' results of test through this part, and } \\
\text { put forward the advice and guidance. }\end{array}$ \\
\hline
\end{tabular}

(2) Function building of the reader

EPUB electronic teaching materials have very high demands for ebook reader: support audio and video, support the home quiz and other interactive behavior, specific functions such as online conversation. We don't find one reader that can cover all the function with a good user interface.

There are some problems to be solved about the reader as following: First of all, it can support a variety of ebook format. Secondly, the reader can show HTML5 element to adapt the new technological development. In addition, the reader can support home quiz and teacher-student interaction module generated by JavaScript. This module is the highlight of electronic teaching materials that comes true through the JavaScript. Finally, EPUB ebook reader must achieve multiplatform support to ensure that students can use various means and kinds of equipment to check and read the electronic teaching materials.

\subsection{The key problems}

There are two problems to be considered mainly in the creation of teaching mode: cut-in point of the application; Learning evaluation and incentive mechanism.

(1) Entry point of the application

When we look for cut-in point during the electronic materials are used in classroom teaching, the key point is to grasp the advantages of electronic teaching materials and the key problems using the electronic materials. The advantages of the electronic materials are portability, removability, interesting multimedia elements bring, real-time test feedback and evaluation. Therefore the cut-in point of application of the electronic teaching materials should first focus on course knowledge that students feel boring in the traditional classroom teaching mode, such as Chinese, English and other strong theoretical course, in the hope of improving students' learning interest and the learning results through electronic teaching materials.

The reform of classroom teaching model aims to strengthen students' initiative in learning and improve the teachers and students' comprehensive quality. These electronic teaching materials call the relevant historical event and audiovisual together, therefore students can pay its biggest learning interest and learning initiative in the learning process.

(2) Learning evaluation

Correct investigation and evaluation of learning achievement for the electronic materials users is the necessary condition to guarantee the continuous learning. The evaluation of students not only confirms the students' learning results, but also includes the recognition of students' learning behaviors. Evaluation contents must include learning behavior, learning achievement, test scores, students' discussion process and other performances. Evaluation of learning is to encourage students to study with the electronic teaching materials through the comprehensive investigation. Every student has its shining lights, and the teacher must be good at catching it. 
In the class with electronic teaching materials, the teacher is easy to achieve the students' individual evaluation. Teachers can use many ways to realize the evaluation of students fast, with multimedia ebook as platform and with mobile devices as the carrier. Classroom assessment is based on the diversification of evaluation, and focuses on process and comprehensiveness of evaluation.

Table 2 The process of evaluation

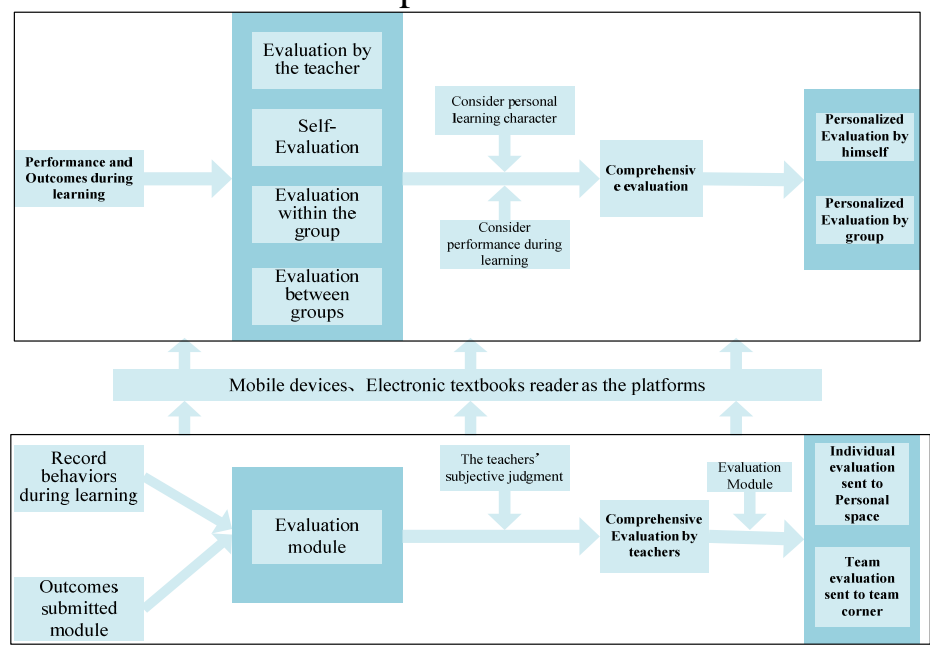

The evaluation should include comprehensive study state and changes. According to the specific teaching activities, evaluation involves evaluation of teachers, self assessment, student assessment, intra-group assessment, and assessment in all groups. Electronic materials greatly improved the efficiency and comprehensive of evaluation, and bring teachers and students new teaching and learning experience.

\section{The significance of EPUB electronic teaching materials in classroom teaching}

The electronic teaching materials, as a kind of high quality new curriculum resources, enrich teaching form, improve junior students' interest in learning, broaden the students' horizons and improve teachers' teaching efficiency. The most important thing is to make full use of the electronic materials brought about by the new tools and methods. The study of application of electronic teaching materials in classroom teaching, form a certain design mode and application mode. It provides a reference for the actual effect of application and a large-scale promotion of electronic teaching materials, but also provides new ideas for the information study.

\section{Reference}

[1]Wei Danyi. Is it feasible to Spread Ebook in China[J]. Information on Publication,2010.10.

[2]Luo Rong. Design and Development of Ebook[J]. China Educational Technology,2006.2.

[3]Yang Dejun. The Value and Problem of Persuing Ebook[J]. Middle and Primary school Management, 2011.3.

[4]Zhang Panfeng. Development of Chinese Ebook in Primary School based on Multiple Intelligence Theory [J]. Electronics World, 2011.11.

[5]Guo Yulian. Discuss of Classroom teaching mode reform[J].Education Theory and Education Practice,2012.10(10):57-60.

[6]Li Fangyuan. Discuss of Ebook in Pad's era[J].Modern Educational Technology,2011(12):124-126.

[7]Huang Ronghuai. Design and Development of Ebook for Information-based learning style [J]. Open Education Research,2012.6(3):27-33. 